\title{
Influência do tempo e da temperatura de armazenamento do sangue de caprinos submetido a análises bioquímicas
}

Felipe Eduardo Dal Mas", Matheus Morillo Bär, Luana Gomes Fernandes, Maria Victória Ferreira Barreiros, Lindomar Fernandes Pessoa, Marla Schneider, Leiluana Camila Rettig, Pedro Argel Zadinelo Moreira, Marilene Machado Silva, Erica Cristina Bueno do Prado Guirro

Universidade Federal do Paraná (UFPR), Curitiba, PR, Brasil

*Autor correspondente

e-mail: dalmasfelipe@gmail.com

\section{Resumo}

Os exames laboratoriais são extremamente úteis na rotina clínica veterinária por sua capacidade de fornecer informações acerca do paciente, colaborando para um melhor diagnóstico do médico veterinário. Desta maneira, cada vez mais este tipo de exame complementar é solicitado; entretanto, realizar estes exames a campo é difícil, e destinar amostras coletadas a campo, armazenando e transportando-as a um laboratório de análises clínicas, torna-se necessário. Diante disso, para que se tenha um resultado correto, confiável, é indispensável conhecer qual a melhor condição de armazenamento e o tempo limite para tal, o que configura o objetivo deste trabalho. Para a realização deste experimento, foi coletado sangue venoso de oito caprinos, $112 \mathrm{ml}$ de cada animal, distribuídos em 14 tubos secos e 14 com fluoreto de sódio, sendo sete de cada um desses mantidos sob refrigeração $\left(4^{\circ} \mathrm{C}\right)$ ou em temperatura ambiente $\left(22^{\circ} \mathrm{C}\right)$. Com estas amostras, foram realizados exames bioquímicos em T0 (imediato após a coleta) e após 2h (T2), 4h (T4), 8h (T8), 12h (T12), 24h (T24) e 48 h (T48). A análise dos dados foi baseada nas médias obtidas em cada tempo, sendo interrompido o processamento das amostras quando os resultados de determinado tempo diferiram mais que 6\% (acima ou abaixo) dos valores obtidos em T0. Assim, ao interromper o exame já determinouse o tempo limite para a realização do mesmo. 0 tempo máximo de cada variável sob refrigeração e temperatura ambiente foi, respectivamente: creatina quinase T0h e T0h; ureia T2h e T0h; lactato T2h e T2h; aspartato aminotransferase T4h e T12h; creatinina T4h e T48h; gama-glutamil transferase T12h e T24h; albumina T24h e T0h; proteínas totais T24h e T24h; glicose T8h e T8h. Deste modo, quando compradas as temperaturas de conservação, podemos concluir que há diferença entre elas, permitindo tempos maiores de armazenamento para alguns testes. Quanto ao tempo, existe influência, porém é possível o processamento das amostras horas após a coleta, em tempos variáveis para cada exame. 